\title{
¿Castigar a las organizaciones armadas? Los intentos de persecución penal a las guerrillas en el marco de la reapertura de los juicios por crímenes de lesa humanidad (Argentina 2003-2007)
}

\author{
Punish the armed organizations? \\ Attempts to prosecute the guerrillas in the framework of the reopening of trials \\ for crimes against humanity (Argentina 2003-2007)
}

Lucía Quaretti ${ }^{*}$

\begin{abstract}
Resumen: Entre 2003 y 2007 en Argentina se llevaron a cabo una serie de medidas legislativas y judiciales que permitieron reanudar el juzgamiento por los crímenes cometidos durante la última dictadura militar. Para reabrir los juicios, fue crucial la tipificación de los delitos como "de lesa humanidad". El presente artículo analiza cómo dos intentos de culpabilizar a las organizaciones armadas - a Montoneros por la muerte de los militantes que participaron de la "operación Contraofensiva" y al Ejército Revolucionario del Pueblo por el asesinato del coronel Larrabure- contribuyeron a construir una interpretación específica de aquella categoría penal.
\end{abstract}

Palabras clave: crímenes de lesa humanidad, Montoneros, Ejército Revolucionario del Pueblo, justicia penal

\begin{abstract}
Between 2003 and 2007 in Argentina a series of legislative and judicial measures were carried out. Those mesures allowed to resume the trial for the crimes committed during the last military dictatorship. To reopen the trials, it was crucial to classify dictatorial crimes as "crimes against humanity". This article analyzes how two attempts to blame the armed organizations -Montoneros for the deaths of the militants who participated in the "Operación Contraofensiva" and the Ejército Revolucionario del Pueblo for the murder of Colonel Larrabure- contributed to construct a hegemonic interpretation of that one criminal category.
\end{abstract}

Key words: crimes against humanity, Montoneros, Ejército Revolucionario del Pueblo, criminal justice

Recibido: 4 diciembre 2017

Aceptado: 17 enero 2018

\footnotetext{
* Argentina. Licenciada en Sociología y Doctoranda en Ciencias Sociales por la Universidad de Buenos Aires. Maestranda en Ciencia Política por el Instituto de Altos Estudios Sociales. Universidad Nacional de San Martín. Becaria Doctoral del Consejo Nacional de Investigaciones Científicas y Técnicas (2013-2018). Lugar de trabajo: Instituto de Investigaciones Gino Germani. Facultad de Ciencias Sociales. Universidad de Buenos Aires. Correo electrónico: luciaquaretti@gmail.com
} 


\section{Introducción**}

Argentina es mundialmente conocida por haber juzgado los delitos cometidos durante la dictadura militar que tuvo lugar entre 1976 y 1983 en tribunales penales civiles. El enjuiciamiento de los criminales de estado se desarrolló en dos etapas. La primera tuvo lugar entre 1983 y 1987: en ese lapso se celebró el Juicio a las Juntas en el cual las cúpulas castrenses fueron condenadas como autoras del plan masivo y sistemático de secuestros, torturas y desapariciones ejecutado sobre la población civil. A partir de 2003, se inició el segundo ciclo de implementación de la justicia retributiva, que esta vez podría alcanzar a policías, militares de bajo rango y también a actores económicos que habían actuado en complicidad con el poder militar.

$\mathrm{Si}$ bien los miembros de las organizaciones armadas se encontraban entre las principales víctimas de los crímenes dictatoriales, también fueron perseguidos penalmente en los dos períodos mencionados, aunque bajo condiciones muy distintas en cada uno. Durante el primer ciclo un decreto presidencial ordenó el procesamiento de sus cúpulas por delitos comunes a los cuales les asignó finalidades políticas. En el segundo ciclo, el juez Claudio Bonadío detuvo en 2003 a los ex jefes montoneros Roberto Perdía y Fernando Vaca Narvaja al acusarlos de la muerte de trece militantes que habían regresado a Argentina desde el exilio en el marco de la operación Contraofensiva. En 2007 el fiscal Claudio Palacín de la ciudad de Rosario responsabilizó al Ejército Revolucionario del Pueblo (en adelante ERP) por el asesinato del Coronel Argentino del Valle Larrabure. A pesar de que estos sucesos no generaron demasiadas repercusiones, tuvieron por consecuencia, en el primer caso, el encarcelamiento durante casi un mes de los imputados; en el segundo, el pronunciamiento del Ministerio Público Fiscal que determinó cómo debían actuar los fiscales de la Nación en el caso de que agentes no estatales fueran acusados por crímenes del pasado. Estos efectos nos permiten afirmar que no se trató de hechos soslayables.

El objetivo de este trabajo es describir y analizar los intentos de judicializar a los miembros de las organizaciones armadas durante el inicio del segundo ciclo de los juicios, particularmente entre los años 2003 y 2007, para ver qué concepciones sobre la responsabilidad los justificaron, cómo se articularon con los crímenes de Estado y, finalmente, de qué modo las consecuencias de esas inculpaciones contribuyeron a forjar una determinada interpretación de la categoría "lesa humanidad" que vertebró la reapertura de los juicios.

En relación con las concepciones sobre la responsabilidad, recuperamos el aporte de Karl Jaspers quien -en el contexto de la segunda posguerra, cuando se acusaba al pueblo alemán, concebido como una entidad homogénea, de haber perpetrado el Holocausto- ${ }^{1}$ propuso distinguir cuatro modalidades de culpa a través de una tipología. Para el autor, la

\footnotetext{
** Agradezco la lectura y los comentarios de una versión previa de este texto al Núcleo de Historia Reciente del Instituto de Altos Estudios Sociales.

1 Karl Jaspers, El problema de la culpa. Sobre la responsabilidad política de Alemania, Barcelona, Ediciones Paidós, 1998, 129.
} 
culpa criminal es determinada por un tribunal que impone un castigo a individuos concretos por crímenes concretos. Arendt ${ }^{2}$ profundiza esta cuestión y agrega que un tribunal no puede juzgar sistemas de ideas o creencias, sino solo a personas de carne y hueso por las consecuencias de su acción en el mundo. La culpa moral y la metafísica son admitidas por cada individuo a través de un auto-examen, ante la propia conciencia y ante Dios, respectivamente, y tienen por efecto el arrepentimiento en el foro interno. La política, por su parte, es imputada por la pertenencia a la comunidad política nacional.

Respecto de nuestro análisis, no nos interesa trasladar automáticamente la tipología anterior al caso argentino, sino fundamentalmente subrayar la importancia de distinguir entre tipos de responsabilidad a fin de lograr una comprensión cabal de los procesos violentos que afectaron tanto a las víctimas particulares como a la sociedad en general. Creemos, además, que en el caso argentino, y en consonancia con el reclamo histórico de los organismos de derechos humanos, la diferencia más relevante es la que puede establecerse entre la responsabilidad por los delitos cometidos desde el Estado y la responsabilidad por el resto de los hechos violentos que hayan reconocido motivaciones políticas en su ejecución. ${ }^{3}$

A fin de abordar nuestro objetivo organizaremos el texto del siguiente modo: primero repondremos los principales hechos vinculados con la reapertura de los juicios concentrándonos particularmente en las adjudicaciones de responsabilidad a las organizaciones armadas en el ámbito parlamentario- y el lugar de la categoría "lesa humanidad" en ese marco. Luego abordaremos los casos de la persecución penal de los jefes montoneros y del ERP en 2003 y 2007, respectivamente. Para ello, analizaremos documentos públicos elaborados por distintas instancias del Poder Judicial y la Procuración General de la Nación, como órdenes de detención, órdenes de excarcelación, informes y dictámenes judiciales. Esto indica que nos focalizaremos en las instituciones que atribuyen responsabilidad y no en las motivaciones o la culpabilidad efectiva de los sujetos acusados.

\section{La reapertura de los juicios por crímenes de lesa humanidad}

Existe una explicación bastante generalizada que identifica al posicionamiento de Alfonsín respecto del juzgamiento de los crímenes dictatoriales como una de las variables explicativas de su triunfo presidencial. La propuesta de sancionar penalmente a los ejecutores de la violencia se diferenciaba de la de su contrincante peronista que sintonizaba con el proyecto militar de declarar una autoamnistía y tender un manto de olvido sobre lo ocurrido durante la dictadura. Asimismo, varios analistas enfatizan que el procesamiento penal de los criminales de Estado, según los términos del estado de derecho, funcionaba como un modo de legitimación del nuevo régimen político. En este sentido, el discurso del presidente radical se demarcaba del pasado violento donde los conflictos se habían dirimido

${ }^{2}$ Hannah Arendt, Eichmann en Jerusalén, Barcelona, De bolsillo, 2010.

${ }^{3}$ Para un desarrollo en profundidad sobre el concepto de crímenes de Estado en el caso argentino ver Daniel Feierstein, Juicios. Sobre la elaboración del genocidio II, Buenos Aires, Fondo de Cultura Económica, 2015, 59-64, 106-109. 
a través de la violencia y las armas; en la naciente democracia imperaría la ley y el mejor modo de dar cuenta de ello era someter a los máximos criminales a los tribunales civiles. Enseguida volveremos sobre este punto.

El momento inicial del primer ciclo de persecución penal de los crímenes cometidos durante la última dictadura puede datarse el 13 diciembre de 1983 cuando a través de la sanción del decreto 157 el presidente Alfonsín ordenó el tratamiento penal de las cúpulas militares. Esa acusación siguió su curso, sorteando diversos obstáculos jurídicos y políticos ${ }^{4}$, hasta culminar en la celebración del Juicio a las Juntas en el cual, en diciembre de 1985, los jefes militares fueron condenados como autores del plan represivo. ${ }^{5}$ Este juicio tuvo gran repercusión pública y, junto a la prueba documental reunida en el "Nunca Más", contribuyó a consolidar un relato público sobre el plan represivo dictatorial.

La sentencia del tribunal de la Cámara Federal de Apelaciones ordenaba continuar el juzgamiento sobre militares y policías de menor jerarquía que habían ejecutado la represión. Si bien llegaron a iniciarse varios procesos en este sentido, ${ }^{7}$ no pudieron finalizarse: una buena parte de los militares que debían prestar declaración indagatoria se sublevaron a través de varios levantamientos armados, entre los cuales se destacó el denominado "Carapintada", que tuvo lugar en abril de $1987 .{ }^{8}$ En ese marco, fueron sancionadas el 23 de diciembre de 1986 la ley n 23.492 "de Punto Final” (en adelante PF) y el 6 de junio de 1987 la ley $n^{\circ} 23.521$ "de Obediencia debida" (en adelante OD), que interrumpieron los juicios en curso y clausuraron la posibilidad de abrir nuevas causas. De este modo, como efecto de las presiones militares y también en coincidencia con lo señalado por Alfonsín durante la campaña electoral, el período finalizó con la punición de los jefes de las fuerzas armadas.

\footnotetext{
${ }^{4}$ Entre estos obstáculos sobresalió el problema sobre si el régimen saliente debía ser juzgado por la justicia militar o por la justicia civil. La ley 23.049, denominada ley de "Reforma del Código Militar", vertebró el pasaje de la justicia militar a la justicia civil. La ley se compuso de dos dimensiones principales: la primera refería a la cuestión de la jurisdicción militar versus la jurisdicción civil; la segunda, a la interpretación de la premisa de la obediencia debida en el código militar. Respecto de la jurisdicción, la ley estableció un plazo para que los militares fueran procesados en la justicia castrense. De no cumplirse ese plazo, intervendría la instancia civil. Asimismo, la instancia civil funcionaba como una instancia de apelación (Carlos Acuña y Catalina Smulovitz, "Militares en la transición argentina: del gobierno a la subordinación constitucional", Carlos Acuña, Inés González Bombal, Elizabeth Jelín, Luis Alberto Quevedo, Catalina Smulovitz y Ana Vacchieri (eds.), Juicios, castigos y memorias. Derechos humanos y justicia en la política argentina, Buenos Aires, Nueva Visión, 1993, 19-100; Carlos Nino, Juicio al mal absoluto, Buenos Aires, Emecé, 1997).

${ }^{5}$ Videla y Massera fueron condenados a prisión perpetua e inhabilitación permanente para todo cargo público; Agosti, a cuatro años de prisión e inhabilitación permanente; Viola, a diecisiete años de prisión e inhabilitación permanente; Lambruschini, a ocho años de prisión e inhabilitación permanente. Grafigna, Galtieri, Anaya y Dami Lozo fueron absueltos (Nino, op. cit.,143).

${ }^{6}$ Sobre la construcción de un relato público sobre el plan represivo y su función como prueba jurídica en el juicio a las Juntas ver Emilio Crenzel, La historia política del Nunca Más: la memoria de las desapariciones en la Argentina, Buenos Aires, Siglo XXI, 2008.

7 "El número final de procesados, según declaraciones de Alfonsín a Giussiani, llegó al terminar todas las prórrogas a cerca de 400 oficiales (Gerardo Aboy Carlés, Las dos fronteras de la democracia argentina. La reformulación de las identidades políticas de Alfonsín a Menem, Rosario, Homo Sapiens, 2001, 203).

${ }^{8}$ Para profundizar este tema ver Acuña y Smulovitz, op. cit.
} 
Aunque fueron el centro de la justicia penal, los militares no fueron los únicos actores enjuiciados durante los años ochenta. Al mismo tiempo que Alfonsín decretó el procesamiento de las cúpulas militares, ordenó el enjuiciamiento de los jefes de las organizaciones armadas. Según la orden presidencial impartida a través del decreto 157/83, la persecución penal se correspondía con:

...los delitos de asociación ilícita, instigación pública a cometer delitos, apología del crimen, otros atentados contra el orden público y rebelión; todo ello sin perjuicio de los demás delitos que se pongan de manifiesto en el transcurso de la investigación, y en los que las personas a quienes se refiere el presente decreto hayan intervenido directamente, o como autores mediatos, instigadores o cómplices. ${ }^{9}$

En la fundamentación del decreto la culpa se atribuía, además, por haber instaurado "formas violentas de acción política con la finalidad de acceder al poder mediante el uso de la fuerza" y porque, a través de la ejecución de homicidios, secuestros, atentados a la seguridad común y asaltos a unidades militares, estos individuos habían buscado ocupar militarmente una parte del territorio nacional. De este modo, se adjudicaban finalidades políticas a los crímenes comunes. Por último, el decreto establecía que esos delitos habían obstruido el accionar del gobierno democrático y, finalmente, habían servido: “(...) de pretexto para la alteración del orden constitucional por un sector de las fuerzas armadas (...)". ${ }^{10}$ La idea de que el gobierno militar había usado estos delitos como justificación para perpetrar su plan criminal era la forma en la cual se enlazaba a la violencia insurreccional con la de los actores estatales.

Esta simultánea inculpación de las cúpulas militares y militantes ha recibido numerosas interpretaciones. La más generalizada identifica esta equiparación de responsabilidades a nivel penal como la condensación de lo que se conoce como la "teoría de los dos demonios". Esta "teoría" funcionó como una matriz interpretativa del pasado dictatorial que, sintéticamente, comprende a la violencia pre dictatorial y dictatorial a partir de las siguientes premisas: dos terrorismos o demonios -el de ultraizquierda y el de ultraderecha, primero, y el de ultraizquierda y el poder militar después- se enfrentaron ante una sociedad que permaneció ajena al conflicto entre ellos, aunque en algunos casos pudo padecer las consecuencias de esa violencia que, de ningún modo, había contribuido a gestar. Asimismo, la responsabilidad primigenia pertenece al "demonio de izquierda" ya que este habría iniciado el conflicto al cual el poder estatal habría respondido legítimamente a través de la represión.

La mayoría de los autores coincide en señalar, como dejamos entrever más arriba, en que esta mutua inculpación por parte del gobierno alfonsinista operó como un discurso autolegitimante de la refundación política: el nuevo gobierno democrático se regiría por los principios del estado de derecho, distanciándose así de un pasado en el cual las diferencias

\footnotetext{
${ }^{9}$ Decreto 157/83(Boletín Oficial de la República Argentina, n²5.321, Buenos Aires, 15 de diciembre de $1983,4)$.

${ }^{10}$ Decreto 157/83. Boletín Oficial de la República Argentina, op.cit. El subrayado nos pertenece.
} 
ideológico-políticas se resolvían por la vía de las armas. Aboy Carlés, Crenzel, Lvovich y Bisquert, Novaro y Vezzetti remarcan la idea de que el relato presidencial buscaba inaugurar un nuevo tiempo y, entonces, la narración sobre el pasado adquiría sentido en tanto se subsumía a la intención de fundar un nuevo orden. ${ }^{11}$

Franco, por su parte, sin desconocer lo antedicho, complejiza la cuestión de la teoría de los dos demonios y su vinculación con la inculpación penal de las cúpulas. La autora muestra la existencia de un hiato entre el discurso alfonsinista que pregonaba la mutua responsabilidad penal de jefes guerrilleros y militares y una política de justicia centrada fundamentalmente en el ámbito castrense. El informe de la CONADEP y el juicio a las juntas habían identificado a los militares como los victimarios de una gran cantidad de víctimas que nada tenían que ver con el mundo de la guerrilla y ni siquiera con el mundo de la política. Desde la perspectiva de la autora, Alfonsín tenía una gran dificultad para explicitar "que los desaparecidos eran, en su mayoría, los mismos subversivos a los que, además se acusaba de ser el origen del mal". ${ }^{12}$

Como bien lo muestra la investigación de Franco, esa tensión estaba dada por dos motivos. En primer lugar, porque el esquema interpretativo de dos violencias enfrentadas ante una sociedad externa que las padecía se encontraba vigente al menos desde 1974. El alfonsinismo lo había resignificado en términos republicanos y añadido la metáfora de lo demoniaco, pero una matriz explicativa de tal larga raigambre no podía borrarse en forma inmediata. Esta idea también es compartida por Vezzetti. ${ }^{13}$ En segundo lugar, porque durante los primeros años de la transición democrática la idea de la lucha antisubversiva contaba con vigencia y legitimidad. ${ }^{14}$

Asimismo, la necesidad de mostrar a las víctimas de la represión como inocentes, en tanto desvinculadas del mundo de la militancia, da cuenta, por un lado, del límite de la transición democrática para universalizar los derechos humanos ${ }^{15} \mathrm{y}$ también de la vigencia del consenso antisubversivo. Sería recién con la publicación del Nunca Más y la celebración del juicio a las juntas que ese consenso podría comenzar a horadarse. En un sentido similar, Lvovich y Bisquert señalan que el juicio a los ex comandantes funcionó

\footnotetext{
${ }^{11}$ Aboy Carlés, op., cit.; Emilio Crenzel, "Ideas y estrategias de justicia ante la violencia política y las violaciones a los derechos humanos en la transición política en Argentina (1982-1983)", Claudia Feld y Marina Franco (Dir.), Democracia, hora cero. Actores, políticas y debates en los inicios de la posdictadura, Buenos Aires, Fondo de Cultura Económica, 2015, 81-114; Daniel Lvovich y Jaquelina Bisquert, La cambiante memoria de la dictadura. Discursos sociales y legitimidad democrática, Buenos Aires, Biblioteca Nacional/UNGS, 2008; Marcos Novaro, "Derechos humanos y política democrática Las tareas de la historia y la justicia entre populismo y liberalismo", Pablo Eiroa y Juan Otero (comps.), Memoria y Derecho Penal, Buenos Aires, Fabian Di Placido Editor, 2008, 25-43; Hugo Vezzetti, Pasado y presente. Guerra, dictadura y sociedad en Argentina, Buenos Aires, Siglo XXI Editores, 2002.

${ }^{12}$ Marina Franco, “La 'teoría de los dos demonios' en la primera etapa de la posdictadura”, Claudia Feld y Marina Franco (Dir.), Democracia, hora cero. Actores, políticas y debates en los inicios de la posdictadura, Buenos Aires, Fondo de Cultura Económica, 2015, 75.

13 "La representación bipolar de la violencia política se implantó en la sociedad después de 1973, a partir del rechazo de los atentados y los asesinatos que golpeaban a la opinión pública", Hugo Vezzetti, Sobre la violencia revolucionaria memorias y olvidos, Buenos Aires, Siglo XXI editores, 2009, 23.

${ }^{14}$ Franco, op.cit, 77.

${ }^{15}$ Franco, op., cit., p.75.
} 
como una superación de la teoría de los dos demonios al reconocer la "brutal superioridad de la violencia estatal". ${ }^{16}$

Desde finales de la década del ochenta y, luego, a partir de la ascensión de Menem al gobierno, el problema económico de la hiperinflación y sus consecuencias sociales relegaron del primer plano la cuestión de los crímenes de la dictadura. Sin embargo, esta no estuvo ausente y generó acciones significativas tanto desde el gobierno como del movimiento por los derechos humanos. La medida más significativa tomada por el Poder ejecutivo fue la sanción de los indultos, lo cual significó un abandono de la iniciativa del tratamiento penal de los crimines de Estado. ${ }^{17}$ Esta decisión se justificó en el discurso de la pacificación y la reconciliación nacional. La interpretación del texto de los indultos realizada por Lvovich y Bisquert muestra cómo el sacrificio de la condena al terrorismo de Estado se justificaba en el alcance del bien común. ${ }^{18}$ De acuerdo con Novaro, la retórica de la reconciliación se basaba en la premisa de que "los crímenes cometidos desde el Estado no alcanzaban a deslegitimar lo que las Fuerzas Armadas se habían visto obligadas a hacer en bien del Estado y del país, reprimir a los organizaciones guerrilleras". ${ }^{19}$ De acuerdo con nuestra argumentación, podemos concebir entonces a este relato como un cierto modo de re-emergencia del consenso antisubversivo.

Sin embargo, la política oficial que buscaba abandonar la discusión sobre los horrores del pasado no logró sus objetivos. A partir de las declaraciones de Scilingo y Balza que se refirieron a los crímenes militares desde el ámbito castrense, sin negar los hechos del terrorismo de estado ni justificarlos como excesos y a partir del aniversario del golpe de Estado de 1996, se produjo lo que Lvovich y Bisquert denominan un "boom de la memoria". En este marco, los organismos de derechos humanos recuperaron su poder de convocatoria y de difundir el relato de los crímenes del pasado entendidos como violaciones a los derechos humanos, en esta oportunidad, enlazadas como parte de una misma serie en la cual se incluía la crisis económica del presente. Asimismo, en el plano judicial los organismos lograron la realización de varios juicios ${ }^{20}$ : los juicios por la verdad en los cuales, si bien los acusados no podían ser sancionados dada la vigencia de las leyes

\footnotetext{
${ }^{16}$ Lvovich y Bisquert, op.cit., p.52.

${ }^{17}$ El primer conjunto de indultos $(1002,1003,1004$ y 1005) fue sancionado el 6 de octubre de 1989. El segundo (2741 a 2747) el 29 de diciembre de 1990 (Leonardo Filippini, "La persecución penal en la búsqueda de justicia”, Centro de Estudios Legales y Sociales y Centro Internacional para la Justicia Transicional, Hacer justicia: nuevos debates sobre el juzgamiento de crímenes de lesa humanidad en Argentina, Buenos Aires, Siglo XXI editores, 2011, 19-48). Estos decretos retiraron la condena de las cúpulas de las organizaciones militantes armadas, de las juntas dictatoriales y de quienes habían participado en las rebeliones militares durante 1987 y 1989 (Ricardo Lorenzetti y Alfredo Kraut, Derechos humanos: justicia y reparación. La experiencia de los juicios en Argentina, Buenos Aires, Sudamericana, 2011, 99).

18 Idem.

${ }^{19}$ Novaro, op.cit., 40.

20 Elizabeth Jelín, "Les mouvements sociaux et le pouvoir judiciaire dans la lute contre l'impunité". Mouvements, 47-48, 2006/5, 82-91. Yanina Guthmann, "Sociedad civil y derecho internacional de los derechos humanos en Argentina" Perfiles latinoamericanos, 16, 32, 2008 (Recuperado de: http://www.scielo.org.mx/scielo.php?pid=S0188- 76532008000200006\&script=sci_arttext). Kathryn Sikkink, La cascada de la política. Cómo los juicios de lesa humanidad están cambiando el mundo de la política, México, Gedisa, 2013.
} 
de PF y OD, los familiares de las víctimas podían obtener el derecho de conocer la verdad; 21 además, se realizaron juicios por la apropiación de menores, ya que ese delito había quedado excluido de las leyes "de perdón”. Estos redundaron, por ejemplo, en la prisión preventiva de Videla y Massera. Finalmente, tuvieron lugar juicios en el exterior. ${ }^{22}$

El gobierno de Kirchnner implicó una nueva etapa en el tratamiento de los crímenes del pasado. Tanto Novaro como Lvovich y Bisquert coinciden en señalar que en este momento la cuestión de los derechos humanos volvió a cobrar un lugar central. Según nuestra mirada, esa centralidad puede observarse en tres planos distintos. El primero refiere a una serie de medidas institucionales llevadas a cabo por el Poder ejecutivo tales como la consignación del predio de la Escuela de Mecánica de la Armada (ESMA) para funcionar como un espacio de memoria, la declaración del 24 de marzo como feriado nacional y la jerarquización de la Secretaria de Derechos Humanos, entre otras.

El segundo plano tiene que ver la instauración de una determinada narrativa sobre los crímenes del pasado. Novaro y Lvovich y Bisquert afirman que la misma se condensa en la reversión del Prólogo del Nunca Más de 2006 y que coincide, en gran parte, con el relato sostenido por los organismos de derechos humanos. ${ }^{23}$ Por una parte, este concibe al plan criminal dictatorial como un medio para instaurar un sistema económico neoliberal. ${ }^{24}$ En relación a lo que aquí nos ocupa, esta matriz interpretativa niega cualquier tipo de relación entre el accionar de la guerrilla y los crímenes de Estado y omite cualquier referencia sobre la violencia de las organizaciones armadas. El análisis del acto conmemorativo del golpe en marzo de 2004, ejemplifica esta cuestión: allí la reivindicación de la militancia realizada por el presidente fue altamente selectiva, dado que ocluyó su dimensión revolucionaria. Asimismo, el primer mandatario presentó a estos grupos como el antecedente inmediato de su gobierno y olvidó que la democracia liberal no formaba parte del ideario militante. ${ }^{25}$ En esta misma línea, Montero muestra cómo la rememoración del discurso presidencial sobre la militancia setentista silenció sus aspectos más trágicos, evitó el debate sobre la responsabilidad vinculado a los hechos violentos y acentuó sus rasgos fraternales, heroicos y voluntaristas. ${ }^{26}$ Tanto para Lvovich y Bisquert como para Novaro, esta narrativa funcionó, para un presidente cuyo caudal electoral había sido bajo, como un modo de incrementar su legitimidad. $^{27}$

\footnotetext{
${ }^{21}$ Pablo Scatizza, Un Comahue violento: dictadura, represión y juicios en la norpatagonia argentina, Buenos Aires, Prometeo, 2016, 241.

${ }^{22}$ Lorenzetti yKraut, op.cit.

${ }^{23}$ Novaro, op.cit.; Lvovich y Bisquert, op.cit.

${ }^{24}$ Paula Canelo, La política secreta de la última dictadura argentina (1976-1983), Buenos Aires, Edhasa, $2016,32$.

${ }^{25}$ Lvovich y Bisquert, op.cit., 83.

26 Ana Soledad Montero, iY al final un día volvimos! Los usos de la memoria en el discurso kirchnerista (2003-2007), Buenos Aires, Prometeo, 2012, 116-117.

27 “Aquella memoria del regimen militar que comenzó a configurarse en el contexto mismo de la represión a partir del esfuerzo de los organismos de derechos humanos resulta en nuestros días la representación predominante, una vez que en los últimos años este relato fue asumido como propio, casi por completo, por el Estado. Como señaláramos, esta novedad permite, por un lado, restablecer a los derechos humanos como uno de los fundamentos centrales de la legitimidad democrática, aunque por otro los convierte en una señal de
} 
Finalmente, la tercera dimensión vinculada con el nudo de nuestro análisis refiere a la reanudación de los juicios por los crímenes de Estado. ${ }^{28}$ Sintéticamente, las principales medidas que permitieron concretar la reapertura fueron, en 2003, la propuesta del poder Ejecutivo de otorgar jerarquía constitucional a la "Convención sobre la imprescriptibilidad de los crímenes de guerra y de lesa humanidad" y la declaración del Legislativo sobre la invalidez de las leyes de PF y OD. Asimismo, en 2004, en el fallo "Arancibia Clavel", el voto mayoritario de la Corte Suprema declaró la validez constitucional de la "Convención sobre la imprescriptibilidad de los crímenes de guerra y lesa humanidad"; en 2005, en el fallo "Simón", estableció la inconstitucionalidad de las leyes de PF y OD; finalmente, en 2007, en el fallo "Mazzeo", determinó la inconstitucionalidad de los indultos.

Todos esos pronunciamientos concibieron a los crímenes dictatoriales como delitos contra la humanidad. Este tipo penal determina la imprescriptibilidad, la prohibición de la amnistía y de la exceptuación de la responsabilidad penal en términos de la eximente de la obediencia debida. El instrumento del derecho internacional que codifica la figura es el Estatuto de Roma, que entró en vigor en julio de 2002. Allí, un delito contra la humanidad es definido como cualquiera de una serie de actos - entre los que se mencionan el asesinato; el exterminio; la encarcelación u otra privación grave de la libertad física; la tortura; la persecución de un grupo con identidad propia fundada en motivos políticos, raciales o nacionales, entre otros; la desaparición forzada de personas y el crimen del apartheid"cuando se cometa como parte de un ataque generalizado o sistemático contra una población civil y con conocimiento de dicho ataque". ${ }^{29}$ Podemos observar que la codificación no delimita un tipo de sujeto social -ya sea estatal, civil o militar- que porte la exclusividad de su ejecución. Sin embargo, según la interpretación del Máximo Tribunal argentino, en sintonía con una tradición jurídica vigente desde los juicios de Núremberg, solo los agentes estatales pueden perpetrar este tipo de crímenes. ${ }^{30}$ Enseguida veremos cómo el rechazo a los intentos de persecución penal de las organizaciones armadas contribuyó a consolidar esa lectura.

Antes de analizar los intentos de persecución penal, vale detenernos en las adjudicaciones de responsabilidad que tuvieron lugar en el debate parlamentario sobre las leyes de PF y OD. Si bien la culpabilización de las organizaciones armadas adquirió sentidos distintos en cada caso, el ámbito legislativo apareció como un antecedente de lo

\footnotetext{
identidad partidaria, lo que conlleva el riesgo de la banalización y la instrumentalización” Lvovich y Bisquert, op. cit., 91.

${ }^{28}$ Lorenzetti y Kraut, op. cit. y Lucía Quaretti, ¿Quiénes merecen ser castigados? La configuración de un régimen de responsabilidad por la violencia del pasado reciente (Argentina, 2003-2007), Tesis para optar por el título de Magister en Ciencia Política, Buenos Aires, Instituto de Altos Estudios Sociales, Universidad Nacional de San Martin, 2017.

${ }^{29}$ Art 7 del Estatuto de Roma, de la Corte Penal Internacional, A/CONF.183/9, de 17 de julio de 1998. Disponible en:

http://www.un.org/spanish/law/icc/statute/spanish/rome_statute(s).pdf y http://www.acnur.org/fileadmin/scripts/doc.php?file=fileadmin/Documentos/BDL/2002/0033.

${ }_{30}$ Sikkink, op. cit.
} 
que luego ocurrió en el juidicial. ${ }^{31} \mathrm{El}$ hecho de que esta cuestión haya sido abordada en una discusión que debía versar sobre la validez constitucional de normas que regulaban la extensión de la culpa penal al interior de las jerarquías castrenses y policiales puede interpretarse como el signo de que el problema de la responsabilidad por la violencia y los crímenes del pasado no era un asunto completamente clausurado. La intervención del diputado Ricardo Argentino Bussi (Fuerza Republicana), quien acompañó su discurso con una inserción de treinta y cuatro páginas, compuesta por un listado de secuestros y asesinatos atribuidos a las organizaciones insurreccionales armadas, sobresalió en este sentido:

...En ese entonces ["cuando recuperamos la democracia"] se produjo el juzgamiento de los principales responsables de la violencia pasada. Se enjuicio y condenó a las juntas militares y a los máximos referentes de los Montoneros y del Ejército Revolucionario del Pueblo (...). Llama poderosamente la atención que los organismos autodenominados defensores de los derechos humanos nada dicen de lo que ha sucedido desde el 24 de marzo de 1976 para atrás. Parecería que cuando mata la derecha son criminales y genocidas, pero cuando mata la izquierda se trata de reivindicaciones sociales. Esto es producto de que miramos la historia con un solo ojo.

(...) Hay que terminar con estas cuestiones que no sirven para nada. Nadie devolverá los muertos de las señoras de Carlotto o Berdina. Nos tenemos que hermanar todos los argentinos para empezar a construir la Nación que nos merecemos. ${ }^{32,33,34}$

${ }^{31} \mathrm{La}$ atribución de responsabilidad a las organizaciones armadas adquirió distintas formas en el discurso militar. Sobre este asunto ver Salvi, op.cit. Asimismo, vale destacar que, como mostramos en el cuerpo del texto, el Diputado Ricardo Argentino Bussi, hijo del General Antonio Domingo Bussi, autor de numerosos crímenes de lesa humanidad, fue una de las voces destacadas en pronunciarse sobre este asunto.

${ }^{32}$ Diario de sesiones de la Cámara de Diputados de la Nación, $12^{\circ}$ reunión 4ta sesión ordinaria (especial), 12 de agosto de 2003, 1601-1635.

33 Ibid., 1553-1555. Esta intervención de Bussi generó abucheos y silbidos en contra, tanto desde los palcos como desde la butacas del recinto (La Nación, 12 de agosto de 2003), así como el pedido de una sanción por parte de la diputada Stella Maris Córdoba (Frente para la Victoria), quien señaló: “(...) quiero plantear una cuestión de privilegio por la conducta asumida en este recinto por el señor diputado Bussi, al haber formulado expresiones antidemocráticas y haber agraviado también a mucha gente que se encuentra en la plaza (...) que pertenece (...) a organismos defensores de los derechos humanos, que han tenido una militancia permanente por esta conquista. (...) A su vez pido, que cuando tengamos el número adecuado para votar, la Cámara resuelva la aplicación de una sanción al señor Diputado Bussi, si es posible en esta misma sesión" (Diario de sesiones de la Cámara de Diputados de la Nación, op.cit., 1558).

34 Aunque no se extendió en igual longitud y no especificó cuáles eran los hechos atribuidos a las organizaciones armadas, el diputado Mauricio Bossa (Ucedé-Córdoba) se pronunció en un sentido muy similar al de Bussi: “(...) si queres hacer realidad aquel apotegma del 'nunca más' (...) debemos decir 'nunca más' al terrorismo de Estado, pero también al terrorismo de aquellos mesiánicos que invocando el poder del pueblo han matado a sus congéneres, a sus connacionales. Tenemos que decir 'nunca más' a la violencia para que en el futuro no haga falta volver a debatir sobre la posible nulidad de las leyes de las cuales nos tengamos que arrepentir" (Ibid.,1556-1557). En un sentido similar se pronunció el diputado Miguel Antonio Jobe (Unidad federalista) en su inserción: "yo (...) quiero mirar hacia adelante con los ojos bien abiertos, no para esquivar a esos argentinos que van en nuestro camino común y que recorremos hoy, sino para que todos 
Además, detectamos que las referencias sobre la violencia insurreccional aparecieron a través de la equiparación entre quienes habían sufrido los hechos perpetrados por los grupos revolucionarios y quienes habían padecido la violencia estatal. Este argumento puede enmarcarse en lo que Valentina Salvi identifica como la cuarta fase de la memoria institucional castrense sobre la dictadura. Esta abandona el relato centrado en la historia de la lucha contra la "subversión" y, en su lugar, propone la igualación entre militantes y militares en tanto víctimas de la violencia generalizada de la época. ${ }^{35}$ El Senador Pablo H. Walter (Fuerza Republicana-Tucumán) y el diputado José Luis Fernández Vanoli (Acción por la República) se pronunciaron en este sentido. Ambos refirieron a la empatía que sentían con el dolor de las víctimas "de uno u otro lado; del dolor en su conjunto, del dolor de los sectores populares peronistas y no peronistas como a aquellos que, formando parte de la familia militar o de las Fuerzas de Seguridad, sufrieron inesperadamente la parte más dura de esos enfrentamientos que ha tenido nuestro país, a través de la pérdida de la vida o de la libertad". 36

Observamos que la atribución de culpa coincidió con la oposición a declarar la nulidad de las leyes "de impunidad" y, por lo tanto, de reabrir los procesos penales a policías y militares. Se trató de una expresión minoritaria ya que, la mayor parte de las argumentaciones en este sentido se concentraron en explicar la lesión jurídica a la división republicana de poderes que significaba la reapertura sin mencionar a las organizaciones armadas. ${ }^{37}$ Así, la coincidencia entre el abandono de la justicia retributiva y la inculpación de las organizaciones armadas implicó una igualación de la responsabilidad de los militares y de las organizaciones guerrilleras en la violencia del pasado. Según esta opinión, al tratarse de violencias equiparables, el castigo de solo una de ellas resultaba injusto. Pero la restitución de la balanza de justicia no debería ocurrir a través del castigo de ambos actores; sino mediante una orientación hacia el olvido de las cuestiones del pasado y el abandono de la solución retributiva.

podamos vivir superándonos en una nación mejor. Pero si me obligan las mayorías mediáticas a trasladarme de otra forma, quiero que ese espejo retrovisor enfoque a todo el pasado, el de la izquierda y el de la derecha que sumieron al país en una guerra que parece hoy que nadie quisiera asumir."(Ibid., 1715).

35 Valentina Salvi, De vencedores a víctimas. Memorias militares sobre el pasado reciente en la Argentina, Buenos Aires, Biblos, 2012.

${ }^{36}$ Diario de sesiones de la Cámara de Diputados de la Nación, op.cit., 1559 y Diario de sesiones de la Cámara de Senadores de la Nación, $17^{\circ}$ reunión, 11va sesión ordinaria, 20 y 21 de agosto de 2003, 4738.

${ }^{37}$ La mayor parte de los senadores y diputados que se opusieron a declarar la nulidad de las leyes entendieron que si el Poder Legislativo nulificaba leyes que él mismo habían sancionado, se incurría en una violación de la división republicana de poderes, ya que declarar la nulidad de una ley es una competencia exclusiva del Poder Judicial (Diario de sesiones de la Cámara de Diputados, op.cit.; Diario de sesiones de la Cámara de Senadores, op.cit). 


\section{Los intentos de imputación de responsabilidad penal a los miembros de las organizaciones armadas durante la reapertura de los juicios}

\section{Las detenciones de los ex jefes montoneros}

Inmediatamente después de aprobada la invalidez de PF y OD y de la reanudación de dos causas judiciales ${ }^{38}$, tuvo lugar el primer intento de castigar penalmente a los jefes de las organizaciones armadas. El 13 de agosto de 2003, Claudio Bonadío, juez titular del juzgado nacional en lo criminal y correccional federal $n^{\circ} 11$, arrestó a Fernando Vaca Narvaja y Roberto Perdía. Las detenciones se enmarcaron en una causa judicial que investigaba a los miembros del Batallón 601 del Primer y Segundo Cuerpo de Ejército por su participación en el plan represivo. La orden de arresto de los ex jefes montoneros se fundamentó en su presunta responsabilidad por el secuestro y la desaparición de trece militantes ${ }^{39}$ de la organización que habían participado de la segunda Contraofensiva en 1980. ${ }^{40}$ Además, Bonadío ordenó la captura internacional por los mismos cargos de Mario Firmenich, principal jefe de la agrupación, pero este no pudo ser capturado porque se encontraba prófugo. En septiembre del mismo año las detenciones adquirieron el status de prisión preventiva y los acusados fueron encarcelados. ${ }^{41}$

Bonadío fundamentó sus acusaciones mediante la reconstrucción histórica de la segunda Contraofensiva mediante una multiplicidad de fuentes. ${ }^{42}$ Así, aseveró, a partir de

${ }^{38}$ El 13 de agosto de 2003 la Cámara de Diputados declaró la nulidad de las leyes a través de la sanción de la ley 25.778 y la Cámara de Senadores convalidó esa decisión el 20 de agosto de 2003. En septiembre, la Cámara de Apelaciones en lo Criminal y Correccional Federal de Buenos Aires decidió reabrir las causas "ESMA" y "I Cuerpo de Ejército" y, así, se hizo eco de la decisión parlamentaria y la fortaleció (Rodolfo Yanzón, 2011, "Los juicios desde el fin de la dictadura hasta hoy", Gabriel Andreozzi (coord.), Los juicios por los crímenes de lesa humanidad en Argentina, Buenos Aires, Atuel, 2011, 146).

${ }^{39}$ Los trece militantes montoneros que regresaron a la Argentina en el marco de la segunda contraofensiva, cuyas muertes eran abordadas en la causa, fueron: Julio César Genoud, Verónica María Cabilla, Jorge Oscar Benitez Rey, Angel Servando Benitez, Lía Mariana Ercilia Guangiroli, Angel Carbajal, Matilde Adela Rodríguez de Carabajal, Raíl Milberg, Ricardo Marcos Zuker, Ernesto Emilio Ferre Cardozo, Miriam Anotio Fuerihs, Marta Elina Libenson y Angel Horacio García Fuentes (Poder Judicial de la Nación, auto de prisión preventiva de Fernando Vaca Narvaja y Roberto Perdía, Buenos Aires, 16 de septiembre de 2003, 53).

${ }^{40}$ La denominada "Contraofensiva montonera", que tuvo una primera versión en 1979 y una segunda 1980, consistió en un operativo organizado por la organización Montoneros que, partiendo del diagnóstico que indicaba que la dictadura se encontraba debilitada, consideraba que algunas operaciones armadas y propagandísticas podían contribuir a su derrota. La mayor parte de los militantes que participaron de la segunda Contraofensiva fueron secuestrados y desaparecidos por el gobierno militar (Richard Guillespie, Soldados de Perón. Historia crítica sobre los Montoneros, Buenos Aires, Sudamericana, 2008). Sobre la contraofensiva montonera ver Hernán Confino, "La contraofensiva estratégica montonera en las memorias de sus participantes: Crónica de un objeto polémico", Aletheia, 6, 11, 2015, 1-22. y Hernán Confino, "Tensiones de un retorno: La Contraofensiva Estratégica Montonera de 1979 y 1980 en Argentina” Izquierdas, 28,2016, 274-291.

${ }^{41}$ Poder Judicial de la Nación, op.cit.

${ }^{42}$ Las fuentes empleadas incluyeron tanto fuentes historiográficas como, por ejemplo, el clásico texto de Gillespie sobre Montoneros, producciones de los imputados en el momento de los hechos, documentos elaborados por la inteligencia de las Fuerzas Armadas y cables desclasificados del aparato de inteligencia de 
variados argumentos y pruebas, que los acusados sabían que el operativo iba a fracasar y que los militantes iban a ser capturados, pero que, a pesar de ello, habían decidido enviar a las víctimas a su muerte. Inicialmente, señaló que la primera Contraofensiva había demostrado que el aparto logístico empleado había fracasado en el alcance los fines propuestos. Sin embargo, los imputados habían optado por mantener la misma estructura logística para llevar a cabo su segunda fase. Luego refirió a un documento militar que daba cuenta del conocimiento de las Fuerzas Armadas sobre la "operación guardamuebles", que consistía en retirar material armamentístico de un depósito para realizar sus operativos. ${ }^{43}$ De acuerdo con el juez, Perdía, Vaca Narvaja y Firmenich debían sospechar que las fuerzas militares estaban al tanto de su plan. ${ }^{44}$ En tercer lugar recuperó los testimonios de militantes que habían señalado a sus jefes los problemas que implicaba retomar la lucha armada y que, ante la falta de respuestas, habían abandonado la organización. ${ }^{45}$ Según la mirada del magistrado, habían sido las propias bases las que habían indicado a los imputados el error que constituía retornar al país. Por último, recurrió a textos elaborados y publicados por los detenidos en el momento de los hechos. Según la lectura propuesta por Bonadío, esos escritos mostraban que la cúpula montonera tenía un acabado conocimiento de los métodos represivos que la dictadura empleaba a nivel general y contra su organización en particular. ${ }^{46}$

A la hora de la acusación final y de la calificación jurídica de la responsabilidad, Bonadío adoptó un tono enunciativo sumamente ambiguo. Así, en la conclusión del desarrollo probatorio, expuso lo siguiente:

Que la conducción nacional de la OM sabía, debía saber, o debió saber que al ordenar la continuación de la contraofensiva a partir de marzo de 1980, manteniendo dentro de los parámetros de planificación que la logística en armamentos, explosivos y comunicaciones estaría basada en los elementos que los militantes que se replegaron después de cubrir la etapa del segundo semestre

\footnotetext{
Estados Unidos. La cuestión de la validez de estos informes como prueba en la causa fue objeto de disputa entre los abogados defensores de los imputados y el juez Bonadío. Asimismo, fue uno de los elementos sobre los cuales versó la acusación penal a Bonadío por su mal desempeño en esta causa.

${ }^{43}$ Poder Judicial de la Nación, op. cit., 57.

44 “Que la 'contraofensiva popular' de 1980 copia la estructura logística, de comunicaciones y depósitos de armas de 1979, que debía existir fundada sospecha de la 'operación guardamuebles' era conocida por la inteligencia del gobierno militar, que este hecho no podía ser desconocido por los miembros de la Conducción Nacional de la OM (Organización Montoneros) en cuanto a la cantidad y calidad de las bajas sufridas y con plena conciencia de los métodos de interrogatorio que la inteligencia del Estado Argentino utilizaba con los militantes de la OM detenidos." (Ibid., 45).

45 "Que los principales jefes de la OM solo habían sido cuestionados en por lo menos dos crisis internas de la organización en solo dieciocho meses y que concluyeron con la separación de la OM de militantes de diverso rango y prestigio público, sino que además, importantes integrantes de la contraofensiva de 1979 se negaron a reingresar en 1980 por ejemplo los tenientes que producen la disidencia y entre otros 'Alcides', 'Alberto', ambos integrantes del TEI ${ }^{\circ} 1$, 'la Negra', 'Miguelito quien sería Osvaldo Olmedo habría de estar a cargo del TEI n², y 'José'." (Ibid., 66).

${ }^{46}$ Aquí incluyó, entre otras, una cita de la obra de Roberto Perdía en la cual este señalaba: “...éramos blanco fácil de la represión (...). Influyó decisivamente el conocimiento que había logrado la inteligencia enemiga sobre nosotros, lo que nos tornó particularmente vulnerables...". Ibid., 47.
} 
de 1979 dejaron depositados en los guardamuebles, podían estar comprometidos y que el riesgo de seguridad era excesivo toda vez que fueron detenidos una importante cantidad de militantes de alta jerarquía en la estructura de la OM y aun así y conociendo perfectamente el trato que se le daba a los prisioneros se prosiguió con el plan establecido. [Las cursivas son nuestras] $]^{47}$

Observamos que el juez no pudo afirmar que los ex jefes montoneros hubieran conocido el destino de sus subordinados, sino que admitió que se trataba de una posibilidad. La tonalidad ambigua apareció también en la calificación de la culpa, la cual no era estrictamente penal, sino una responsabilidad política que había devenido en penal. El funcionario definió al primer concepto como un rasgo propio de los colectivos en los cuales las decisiones y acciones de determinados sujetos afectan al resto del grupo, o bien al espacio influenciado por esas decisiones. ${ }^{48}$ En este sentido, señaló que las trece víctimas de la causa habían decidido su regreso en forma voluntaria, pero que las condiciones de su decisión estaban viciadas y que no habían deseado ese regreso. ${ }^{49}$

La caracterización jurídica de la culpa continuó a través de las figuras de dolo eventual y participación. El dolo eventual refiere a la idea de que el criminal actúa sabiendo que las consecuencias de su acción involucran una conducta delictiva y/o riesgosa, pero aun así elige conservar el curso de acción planeado ${ }^{50}$ Respecto de la participación, desde la perspectiva del magistrado, la cúpula de la organización había participado de un delito cuyos autores principales eran los miembros de las Fuerzas Armadas y de Seguridad ${ }^{51}$ :

\footnotetext{
${ }^{47}$ Idem.

48 “Que en este sentido la llamada responsabilidad política por la participación en la toma de decisiones que hacen al comportamiento de colectivos sociales o políticos, muta en responsabilidad penal cuando dichas decisiones y actos propios de carácter comisivo u omisivo son de tal naturaleza que los terceros incluidos en el sistema de influencia de esas decisiones y de esos decisores, son conducidos inexorablemente a un determinado fin, más allá de su propia voluntad. (...) Que en cuanto a los encartadas no se hará un análisis de su responsabilidad penal por separado, toda vez que el hecho imputado lo es en tanto que '... en su calidad de miembro de la Conducción Nacional de la Organización Montoneros participó en la toma de decisión de continuar las operaciones militar en territorio argentino, durante el año 1980, para lo cual se ordenó a [Genoud, Cabilla, Benitez Rey, Benitez, Guangiroli, Carbajal, Rodríguez de Carbajal, Milberg, Zuker, Ferre Cardozo, Antonio Fuerihs, Libenson y García Perez] ingresar a la Argentina a sabiendas de que la logística de la OM estaba seriamente comprometida (..)" (Poder Judicial de la Nación, op.cit., 56-57).

49 “(...) la voluntad de los militantes de la OM, que reingresan en febrero/marzo de 1980, de asumir los riesgos propios de su decisión voluntaria de participar en el proceso de 'resistencia a la dictadura militar' sumándose a la 'contraofensiva popular' estaba totalmente viciada por las condiciones en las que les fue ordenado regresar y más allá que asumieran de manera libre su regreso no quiere decir que lo desearan, así se establece cuando Cristina Zuker sostiene que su hermano y cuñada nunca pensaron que a treinta días de salir de Argentina se les ordenara volver a reingresar."(Ibid., 50).

50 Gustavo Letner, Dolo eventual y culpa con representación, Corte Interamericana de Derechos Humanos, 2015. Disponible en http://www.corteidh.or.cr/tablas/22233a.pdf

51 "La columna medular de este sistema era la estructura de inteligencia de las FF.AA. y de seguridad cuyo control operacional quedó a cargo del Batallón de inteligencia 601 dependiente de la Jefatura II del Estado Mayor General del Ejército Argentino" (Ibid., 2).
} 
Que con convicción necesaria para esta etapa procesal se puede decir que está probado que los miembros de la conducción nacional de la OM no tomaron todos los recaudos necesarios para que sus decisiones no fueran funcionales a la estructura ilegal de represión organizados por el gobierno de las FFAA en el período 1976/83 (...) Que esa responsabilidad, que se le imputa a Roberto Cirilo Perdía y Fernando Vaca Narvaja tiene que ver con la participación necesaria que los mismos tuvieron en los hechos ilícitos cometidos por quienes integraban como parte de la estructura ilegal de represión del estado Argentino y que ejercieron sobre los (...) militantes de la OM que ingresaran al país o a sus países limítrofes entre febrero y marzo de $1980 .{ }^{52}$

La responsabilidad penal fue adjudicada, en última instancia, por la contribución con el sistema represivo militar y, así, los jefes montoneros fueron acusados por delitos que ellos no habían ejecutado directamente, sino con los que, desde esta perspectiva, habían colaborado en contra de sus propios intereses.

El 21 de octubre de 2003 los jueces Horacio Cattani, Martín Iruzún y Eduardo Luraschi, a cargo de la Sala II de la Cámara de Apelaciones, ordenaron la excarcelación de Perdía y Vaca Narvaja; ${ }^{53}$ tras la liberación de sus compañeros, Firmenich, regresó a su hogar en España. ${ }^{54}$ Este tribunal presentó una interpretación de los acontecimientos históricos que refutó la efectuada por Bonadío. En primer lugar, los camaristas afirmaron que cada una de las víctimas había decidido su participación en forma libre e individual y no por la coerción de las cúpulas. Para probarlo, recuperaron el testimonio de Miguel Bonasso, ex miembro de la organización. ${ }^{55}$ En segundo lugar, los tres jueces señalaron que hubiera sido jurídicamente posible imputar responsabilidad penal a Perdía y a Vaca Narvaja si se hubiera probado la existencia de un acuerdo explícito entre ellos y los miembros de las Fuerzas Armadas para exterminar a las trece víctimas de la causa. Sin embargo, en los fundamentos de las detenciones no se habían incluído pruebas en ese sentido. ${ }^{56}$ Por último, en relación con la calificación legal, el tribunal consideró que los hechos de la causa debían ser tipificados como de lesa humanidad. Según su mirada, eran los delitos perpetrados por los miembros del Primer y Segundo Cuerpo de Ejército, del Batallón de inteligencia 601 y las autoridades máximas de los destacamentos de inteligencia 123 y 201 y no la operación

\footnotetext{
52 Ibid., 72-73.

53 Sala II, Cámara Nacional de Casación Penal, Causa $n^{\circ}$ 20.559, Incidente de excarcelación de Vaca Narvaja, Fernando en autos Scagliusi, Claudio Gustavo por privación ilegal libertad personal, 20 de octubre de 2003 y Sala II, Cámara Nacional de Casación Penal, Causa $n^{o}$ 20.561, Incidente de excarcelación de Perdía, Roberto Cirilo en autos Scagliusi, Claudio Gustavo por privación ilegal libertad personal, 20 de octubre de 2003.

${ }^{54}$ La Nación, 21 de octubre de 2003.

55 "'Incluso nosotros hablamos con algunos compañeros que iban a ser enviados al país para tratar de disuadirlos de que no fueran y se unieran a nuestra disidencia, entre otros Frías Alberga y el grupo que él integraba...' (Cfr. fs. 5247), [esta cita] es representativa de la voluntad que movía a quienes fueron privados de libertad y luego desaparecieron por estos acontecimientos." Sala II, Cámara Nacional de Casación Penal, Causa $n^{o}$ 20.559, op. cit., 8-9).

${ }^{56}$ Idem.
} 
Contraofensiva, el conjunto de crímenes a investigar y sancionar. ${ }^{57}$ Asimismo, indicaron que era la condición de agentes estatales de los perpetradores la que habilitaba el uso del tipo lesa humanidad, y por ello no correspondía imputar a los miembros de las organizaciones armadas:

...el acotado número de casos que componen el objeto de investigación de este proceso, debían comprenderse en el más amplio marco de un ataque generalizado y sistemático contra una población civil -entre quienes se encontraban las víctimas- en el que participaron agentes estatales movidos por razones de persecución política o racial. Estas características, en el desarrollo jurídico actual, configuran los elementos salientes que permiten identificar la actividad de un determinado régimen de iure o de facto en su vinculación con los ciudadanos, como crímenes contra la humanidad. En la medida que los hechos de la causa responden a esas cualidades, pueden ser catalogados también como crímenes de lesa humanidad. [Las cursivas son nuestras] ${ }^{58}$

A su vez, la inculpación de los ex jefes montoneros había tenido por consecuencia "[modificar] la perspectiva de la condición de víctimas de quienes padecieron el ilegítimo accionar de agentes estatales de las Fuerzas Armadas o de seguridad durante el período cuestionado" ${ }^{59}$ De ese modo, los camaristas resaltaron la demarcación infranqueable entre perpetradores y víctimas: solo militares y policías podían ocupar el primer lado de la frontera, mientras que el segundo quedaba reservado a los civiles. En este sentido, las detenciones posibilitaron que una instancia superior de la justicia enunciara la interpretación sobre la categoría de lesa humanidad que, ciñendo a sus perpetradores a los agentes estatales, se consolidaría como la lectura dominante durante la reapertura de los juicios. Más tarde, la Cámara Federal de Apelaciones señaló que Bonadío habría incurrido en los delitos de privación ilegítima de la libertad y prevaricato. ${ }^{60}$ Asimismo, en los autos de excarcelación de Perdía y Vaca Narvaja, los camaristas solicitaron al Consejo de la Magistratura que extrajera testimonios y sorteara a quien debería llevar adelante la nueva

\footnotetext{
${ }^{57}$ Ibid., 5.

${ }^{58}$ Idem.

${ }^{59}$ Ibid., 7.

${ }^{60}$ La Nación, 21 de octubre de 2003; Página/12, 22 de octubre de 2003. El delito de prevaricato se encuentra codificado en el Código Penal. El artículo 269 indica: "sufrirá multa de tres mil pesos a setenta y cinco mil pesos e inhabilitación absoluta perpetua el juez que dictare resoluciones contrarias a la ley expresa invocada por las partes o por el mismo o citare, para fundarlas, hechos o resoluciones falsas. Si la sentencia fuere condenatoria en causa criminal, la pena será de tres a quince años de reclusión o prisión e inhabilitación absoluta perpetua". El 270 señala: "Será reprimido con multa de pesos dos mil quinientos a pesos treinta mil e inhabilitación absoluta de uno a seis años, el juez que decretare prisión preventiva por delito en virtud del cual no proceda o que prolongare la prisión preventiva que, computada en la forma establecida en el artículo 24, hubiere agotado la pena máxima que podría corresponder al procesado por el delito imputado".
} 
causa contra el juez federal por los presuntos delitos de acción pública recién mencionados. ${ }^{61}$

El accionar de Bonadío en pos de imputar responsabilidad penal a los ex militantes armados recibió diferentes interpretaciones: desde que beneficiaba al gobierno de Néstor Kirchnner que, al mostrar la puesta en prisión de los ex jefes montoneros, podía presentarse como un tercero imparcial ante la cuestión de la violencia sobre los años setenta; ${ }^{62}$ hasta que constituyó una estrategia de sus opositores para que abandonara el proceso de reapertura de juicios a los militares. ${ }^{63}$

En tanto el juez admitió que quienes habían ejecutado los delitos de la causa en forma directa eran las Fuerzas Armadas y no los acusados, el fundamento principal de la culpa residió en las motivaciones políticas de los ex jefes montoneros y no en los hechos particulares perpetrados por ellos. Asimismo, las bases jurídicas de la acusación fueron mínimas en comparación con el desarrollo de la narración histórica y el aspecto político de la operación Contraofensiva. Si exponemos estos elementos a la luz de la premisa sostenida por Jaspers y Arendt que enunciáramos arriba y que sostiene que la responsabilidad penal es aquella imputada a individuos concretos por hechos concretos, podemos pensar que la acusación de Bonadío solapó distintas nociones o tipos de responsabilidad.

\section{La causa Larrabure}

La "causa Larrabure" constituyó un intento de imputar responsabilidad penal a los miembros del ERP por haber secuestrado y asesinado a Argentino del Valle Larrabure. Este coronel es una figura emblemática en el marco de la cuarta fase de la memoria institucional castrense sobre la dictadura. Dijimos, siguiendo a Salvi, ${ }^{64}$ que esta consiste en igualar a las víctimas de los crímenes dictatoriales con las de la violencia insurreccional en pos de la reconciliación, entendida como el abandono de la persecución penal. Por el contrario, en este caso, la equiparación se tradujo en la búsqueda de la judicialización de los ex militantes armados. La historia procesal de la causa es sumamente compleja y extensa: se inició en 1975 y al momento de escritura de este artículo no ha encontrado una sentencia definitiva. ${ }^{65}$ Aquí nos interesa dar cuenta de lo acontecido durante los años de la reapertura de los juicios.

En octubre de 2007 Claudio Palacín, fiscal general de Rosario, presentó un dictamen ante el Juzgado Federal $\mathrm{N}^{\circ} 4$ de esa ciudad para iniciar una investigación penal sobre el

\footnotetext{
${ }^{61}$ Sala II Cámara Nacional de Casación Penal, Causa n ${ }^{\circ} 20.559$, op.cit.

${ }^{62}$ Así lo interpretó el diario La Nación, a partir de la reacción ante las detenciones del ministro del Interior Aníbal Fernández quien señaló: "Pasó lo que exactamente tiene que suceder: todos iguales ante la ley" (La Nación, 15 de agosto de 2003).

${ }^{63}$ Así lo interpretó Horacio Verbitsky en "La semana de Scioli y la Obediencia Debida" (Página/12, 24 de agosto de 2003).

${ }^{64}$ Salvi, op.cit.

${ }^{65}$ Este texto fue escrito durante septiembre de 2017.
} 
secuestro y el asesinato de Larrabure, ejecutados en 1974 por miembros del ERP. ${ }^{66}$ Palacín afirmó que los delitos de la causa eran crímenes de lesa humanidad y, por lo tanto, correspondía investigar y sancionar a sus autores porque al ser tipificados de ese modo, resultaban imprescriptibles. ${ }^{67}$ Esta calificación se justificaba en el "elemento internacional" incluido en el accionar del ERP, ${ }^{68}$ el cual se manifestaba, por un lado, en la capacidad que había tenido para controlar el territorio argentino, lo cual se comprobaba, primero, a través de un trabajo del historiador Pablo Pozzi que afirmaba que la organización había dominado una porción del suelo tucumano; y segundo por el hecho mismo de que un militar de alto mando hubiera sido secuestrado, dado que, para la acusación, eso representaba una prueba del control territorial. ${ }^{69}$ Según el fiscal rosarino, el elemento internacional también se exponía en la ayuda externa brindada por el gobierno cubano, ya que el apoyo de un gobierno extranjero podía entenderse en términos amplios. En esta causa la prueba del elemento internacional estaría dada, entre otros factores, por las reuniones que habían tenido lugar entre Mario Santucho, líder del ERP, y los jefes revolucionarios cubanos. ${ }^{70}$

Por otra parte, Palacín buscó demostrar que la interpretación dominante en el campo jurídico argentino, que identifica a los militares como los perpetradores y a los civiles como las víctimas de los crímenes de lesa humanidad, podía invertirse. Para ello, recurrió, por un

${ }^{66}$ En palabras del informe los hechos fueron los siguientes: "[Personas que] presumiblemente pertenecían al PRT-ERP, asaltaron y saquearon en agosto de 1974 la fábrica militar de pólvora y explosivos de Villa María. Capturaron a Larrabure y lo mantuvieron privado de su libertad durante un año. En agosto de 1975 el militar habría muerto por asfixia. Su cuerpo fue encontrado dentro de un envoltorio en un camino sin nombre de una zona rural de Rosario, provincia de Santa Fe." (Claudio Marcelo Palacín, Fiscal General, Larrabure, Argentino del Valle s/su muerte, Expte. $\mathrm{N}^{\circ} 18 / 07,30$ de octubre de 2007).

${ }^{67} \mathrm{Si}$ bien el foco de nuestra atención se posa sobre la discusión acerca de la categoría lesa humanidad, no podemos dejar de mencionar que Palacín afirmó que los delitos perpetrados contra Larrabure fueron cometidos en el marco de un conflicto armado interno. (Claudio Marcelo Palacín, Fiscal General, en los autos caratulados "Larrabure, Argentino del Valle s/su muerte, Expte. ํ18/07", 30 de octubre de 2007, pág. 67) y, por eso, podían ser tipificados como crímenes de guerra (Ibid., 76). Estos son regulados por el Derecho Internacional Humanitario cuya normativa se aplica, indistintamente, a civiles y militares, ya sea en el rol de víctimas o perpetradores. En este sentido, el fiscal rosarino afirmó: "Se concluye que la operatividad del Derecho Internacional Humanitario garantiza que las violaciones del artículo 3 común conllevan la responsabilidad penal e individual de quienes las hayan perpetrado, sean agentes del Estado o del grupo disidente, sean combatientes o no combatientes no limitando la responsabilidad a la defensa del Estado." (Ibid., 78).

${ }^{68} \mathrm{Ibid} ., 81$.

69 "El PRT-ERP, en este caso la entidad tras la política subversiva y revolucionaria, en su carácter de organización rebelde insurrecta, ejerció de hecho poder sobre sectores del territorio nacional. (...) A la luz de los elementos de este caso, ¿podemos poner en duda que el Ejército Revolucionario del pueblo (...) tenía control de facto sobre parte del territorio argentino? O en función de lo acontecido en este caso concreto, en el que la víctima -oficial del ejército argentino y por tanto funcionario público de alta jerarquía-, fue sacada de su lugar de trabajo - un cuartel militar-, secuestrada, torturada, mantenida en cautiverio por más de un año y finalmente asesinada, ¿puede dudarse que el ERP se movía fácilmente por el territorio argentino?” (Ibid., 83).

70 "La doctrina y la jurisprudencia internacional tienen dicho que, para la configuración de los crímenes contra la humanidad, el apoyo estatal no tiene por qué estar específicamente referido al acto u actos criminales concretos que se investigan; basta con que el o los Estados involucrados hayan prohijado, alentado y/o tolerado dichas actividades violatorias de los más elementarles derechos humanos, en abierta violación al Derecho Penal Internacional.”(Ibid., 88-89). 
lado, al pronunciamiento del Tribunal Penal Internacional para la ex Yugoslavia, el cual establecía que los agentes estatales no eran los ejecutores exclusivos. De acuerdo con este tribunal, las organizaciones que sin formar parte del Estado tuvieran un efectivo control sobre el territorio, podían ser responsabilizadas por estos delitos. ${ }^{71}$ Además, propuso una interpretación peculiar del término "civil", la cual asoció a la condición de indefensión de Larrabure. Luego de describir las condiciones de su detención, afirmó: "Todo individuo indefenso, independientemente de su estado formal como miembro de una fuerza armada debe considerarse civil. Quedan comprendidos quienes no estén tomando parte activa en las hostilidades, incluyendo los miembros de las fuerzas armadas.",72

A lo largo del dictamen existieron reiteradas referencias a la autoría del ERP en tanto colectivo en los hechos de la causa, pero en ningún momento se identificó a sus miembros en forma individual. Tal como señalamos más arriba, de acuerdo con Arendt y Jaspers, la imputación de responsabilidad penal exige la determinación de hechos específicos y de personas concretas que los hayan perpetrado. En este sentido, la inculpación de Palacín enfrentaba a la imposibilidad de hallar individuos a los cuales acusar ante el tribunal. De acuerdo con Ana Oberlin y Nadia Schujman, abogadas de la agrupación H.I.J.O.S (Hijos por la Identidad y la Justicia contra el Olvido y el Silencio), una inculpación precisa no era posible porque los ideólogos y ejecutores de los hechos perpetrados contra Larrabure habían sido desaparecidos por el gobierno dictatorial. ${ }^{73} \mathrm{El}$ dictamen puede interpretarse entonces considerando que el propósito de su autor no consistía en buscar el castigo puntual de los culpables, sino en cuestionar, primeramente, la idea de que solo los agentes estatales podían ser criminales de lesa humanidad e, indirectamente, la reapertura de los juicios a los militares y policías involucrados en el plan represivo.

Luego de dar a conocer su dictamen, el fiscal solicitó la intervención de la "Unidad de asistencia para causas por violaciones a los derechos humanos durante el terrorismo de Estado" a cargo del Dr. Ricardo Moisés Vázquez, quien, a su vez, elevó una consulta a Jorge Auat y Pablo Parenti, coordinadores de la "Unidad Fiscal de coordinación y seguimiento de las causas por violación a los derechos humanos durante el terrorismo de Estado" (en adelante Unidad Fiscal). ${ }^{74}$ Producto de esa consulta, el 26 de noviembre de

\footnotetext{
${ }^{71}$ (Ibid., 60-61).

72 Ibid., 92.

${ }^{73}$ Las abogadas afirmaron: "más absurdo y paradójico resulta aún en el hecho puntual del secuestro de Larrabure, en el que es de público conocimiento que sus ejecutores e ideólogos fueron asesinados o desaparecidos por la dictadura, aplicándoseles de facto la pena de muerte a sus responsables" (Rosario 12, 23 de agosto de 2008).

${ }^{74} \mathrm{La}$ "Unidad de asistencia para causas por violaciones a los derechos humanos durante el terrorismo de Estado" fue creada por la Procuración General de la Nación en 2004 mediante la resolución PGN 163/04. En marzo de 2007, Esteban Righi, Procurador General de la Nación, creó la "Unidad Fiscal de Coordinación y Seguimiento de las Causas por Violaciones a los Derechos Humanos Cometidas durante el Terrorismo de Estado", con el objetivo de promover acciones tendientes a acelerar la instrucción de las causas reabiertas, asegurar la realización de juicios orales y públicos en cada jurisdicción donde funcionaron centros clandestinos y garantizar en todos los casos la observancia del debido proceso en beneficio de los victimarios y el menor grado de exposición posible de las víctimas. Carolina Varsky, Lorena Balardini, Daniel Martinez, y Julieta Parella, “Justicia y memoria por delitos de lesa humanidad: un 2007 con más deudas que logros",
} 
2007, Auat y Parenti publicaron un informe titulado "Informe sobre la causa 'Larrabure, Argentino del Valle s/su muerte". ${ }^{75}$ Allí señalaron que si bien era indiscutible el carácter atroz de los delitos sufridos por el coronel, estos no podían ser tipificados como crímenes de lesa humanidad ni como crímenes de guerra, ${ }^{76}$ y que el propósito del informe era exponer los argumentos que impedían esa caracterización. ${ }^{77}$

La mayor parte de la argumentación del Informe se vertebró sobre la relación entre los agentes estatales y los crímenes de lesa humanidad. Sus autores recuperaron varias fuentes que destacaban que los perpetradores de este tipo de delitos eran los agentes estatales. Entre estas, incluyeron el recurso de hecho, elaborado en septiembre de 2006 por Esteban Righi, Procurador General de la Nación, sobre la causa "Derecho, René Jesús sobre incidente de prescripción de la acción penal"78 ratificada en julio de 2007 por la Corte Suprema. ${ }^{79}$ Allí, Righi había establecido que la emergencia histórica de la categoría lesa humanidad se vinculaba con la búsqueda de una respuesta penal a las manifestaciones del poder estatal que habían infringido los derechos humanos. ${ }^{80}$

Ahora bien, los autores del Informe reconocieron que el Estatuto de Roma no era concluyente sobre quiénes podían ser los perpetradores de estos delitos y era la Corte Penal Internacional la que debía establecer los criterios al respecto en cada uno de sus pronunciamientos. ${ }^{81}$ Asimismo, señalaron que algunos de los fallos de los tribunales ad hoc, particularmente el fallo Tadic, emitido por el Tribunal Penal Internacional para

Centro de Estudios Legales y Sociales, Derechos Humanos en Argentina, Informe 2007, Buenos Aires, Siglo XXI editores, 2008, 34.

75 Auat, Jorge y Parenti, Pablo, Procuración General de la Nación, Unidad Fiscal de Coordinación y Seguimiento de las causas por violaciones a los Derechos Humanos cometidas durante el terrorismo de Estado, Informe sobre la causa "Larrabure, Argetino del Valle s/su muerte", noviembre de 2007.

${ }^{76}$ Respecto de los crímenes de guerra, Auat y Parenti indicaron que esa figura no era aplicable al caso de Larrabure porque el Derecho Internacional Humanitario solo regula conflictos internacionales; porque juzgar según esa figura implicaría una aplicación retroactiva de la ley penal; porque aunque los desarrollos más recientes de la jurisprudencia internacional incluyeran conflictos internos, el empleo de esa jurisprudencia también significaría una aplicación retroactiva de la ley; y finalmente, porque estaba probado que en Argentina no había existido un conflicto armado interno (Auat, Jorge y Parenti, Pablo op. cit., 4).

${ }^{77}$ Una postura distinta es la de Guariglia, quien considera que no es posible determinar tajantemente si los hechos de violencia insurreccional "pueden quedar comprendidos en las disposiciones del derecho penal internacional" y que, además, esa determinación puede lograrse, en última instancia, a partir del análisis de los hechos concretos, que deberá efectuarse en cada caso. No obstante, entiende que la definición de los crímenes de lesa humanidad involucra el carácter masivo y sistemático a través del cual son implementados estos delitos y que esas características difícilmente podrían corresponderse con la actividad de las organizaciones armadas (Fabricio Guariglia "Crímenes internacionales y actores no estatales Centro de Estudios Legales y Sociales y Centro Internacional para la Justicia Transicional", Hacer justicia: nuevos debates sobre el juzgamiento de crímenes de lesa humanidad en Argentina, Buenos Aires, Siglo XXI editores, 2011, 143-166.

${ }^{78}$ La causa "Derecho, René Jesús" 24.079 no se vincula a los crímenes cometidos durante la última dictadura. Refiere, de acuerdo a lo señalado por Righi, a los hechos perpetrados por el policía René Jesús Derecho contra Juan Francisco Bueno Álvez en 1988.

${ }^{79}$ La Corte Suprema de Justicia de la Nación ratificó los dichos de Righi en el Recurso de hecho "Derecho, René Jesús s/incidente de prescripción de la acción penal- causa n²4.079” en julio de 2007.

${ }^{80}$ Auat, Jorge y Parenti, Pablo, op. cit.,4.

${ }^{81}$ Ibid., 8 . 
Yugoslavia, había reconocido la posibilidad de que agentes no estatales y sin vínculo con lo estatal perpetraran crímenes de lesa humanidad. Sin embargo, este documento exigía que para ser calificados bajo este tipo penal los criminales debían tener capacidad de control sobre el territorio. ${ }^{82}$ Auat y Parenti destacaron la falta de especificidad de las pruebas empleadas por Palacín para fundamentar que el ERP había dominado el suelo tucumano. La única fuente del escrito del fiscal era el texto del historiador Pablo Pozzi, en el cual recuperaba un informe de la Fuerza Aérea Norteamericana sin incluir sus referencias documentales. $^{83}$

Finalmente, el 29 de noviembre, Righi refutó el dictamen de Palacín y negó que los delitos sufridos por el coronel fueran crímenes de lesa humanidad. ${ }^{84}$ Ese pronunciamiento implicó la apropiación en su totalidad de los argumentos empleados en el informe de Auat y Parenti. ${ }^{85}$ Así, sobre la base del trabajo de la Unidad Fiscal, el Procurador General instruyó a los fiscales de la nación a que en todos los casos análogos adoptaran las directivas del informe. ${ }^{86}$ La causa Larrabure funcionó así como un puntapié para determinar que la interpretación correcta de la definición de los delitos contra la humanidad era aquella que establecía que solo los agentes estatales podían ser sus perpetradores. ${ }^{87}$

\section{Reflexiones finales}

Durante los años de la reapertura de los juicios por los crímenes dictatoriales existieron diversas referencias sobre la responsabilidad de las organizaciones armadas por su accionar en el pasado. En primer lugar, mostramos cómo en la discusión parlamentaria sobre la validez de las leyes de PF y OD las inculpaciones a estos actores fueron pronunciadas por quienes se oponían a reabrir los juicios y, por lo tanto, no admitían la distinción entre la responsabilidad de policías y criminales por el plan delictivo perpetrado desde el Estado y los hechos de violencia insurreccional.

En el ámbito judicial, el juez de primera instancia Bonadío y el fiscal Palacín buscaron incorporar a las organizaciones armadas a la órbita de la culpa penal, sin cuestionar, al menos explícita o directamente, la responsabilidad de los agentes estatales. Sin embargo, ambos encontraron graves problemas para imputarla. Bonadío acusó a los ex

\footnotetext{
${ }^{82}$ Ibid., 7.

${ }^{83}$ Ibid., 11.

${ }^{84}$ Esteban Righi, Resolución Procuración General de la Nación n¹58/07, 29 de noviembre de 2007.

${ }^{85}$ Dijo Righi: "El suscripto comparte y hace propios los fundamentos y las conclusiones expuestas en el informe mencionado, al que corresponde remitirse por razón de brevedad" (Idem).

${ }^{86}$ En este mismo sentido interpretó la resolución de Righi la periodista Victoria Ginzberg en un artículo titulado "El boomerang de la justicia" (Página/12, 2 de diciembre de 2007).

${ }^{87}$ El documento elaborado por Righi fue una instrucción general y no especificó si poseía o no carácter vinculante. Así señaló: “Artículo 1: Instruir a los señores físcales por competencia penal que integran el Ministerio Público Fiscal de la Nación para que adopten la interpretación señalada en el informe emitido por la Unidad Fiscal de Coordinación y Seguimiento de las causas por Violaciones a los Derechos Humanos (Res. PGN 14/07), que se adjunta como anexo y forma parte de la presente, y, en consecuencia, en casos análogos al que constituye objeto de ese informe actúen con arreglo a los criterios que allí se indican. Artículo 2: Asignarle a la presente el carácter de instrucción general. Artículo 3: Protocolícese, notifíquese a todos los fiscales con competencia penal de este Ministerio Público Fiscal, Publíquese en el boletín oficial del organismo a través de la página web institucional y, oportunamente archívese.” (Esteban Righi, op. cit).
} 
jefes montoneros por sus motivaciones subjetivas, pero no por delitos concretos, ya que él mismo reconoció que los militantes de base habían muerto a manos de las Fuerzas Armadas. La inculpación de las guerrillas a partir de sus motivaciones políticas y del enlace de su accionar con el de los agentes estatales no era totalmente novedosa: el decreto del presidente Alfonsín que ordenó su enjuiciamiento contuvo estos dos elementos. A diferencia de los años de la reapertura, en aquella oportunidad había sido posible adjudicarles crímenes comunes incluidos en el código penal que podían tener correspondencia con los hechos que habían perpetrado. Palacín, por su parte, pudo identificar una acción particular, pero no a sus autores, dado que acusó al ERP en tanto colectivo de haber secuestrado y ejecutado al Coronel Larrabure.

Bonadío buscó involucrar a los guerrilleros en el plan represivo a través de la complicidad, mientras que Palacín intentó penalizarlos por actos de violencia insurreccional. En ambos casos, otras instancias del poder Judicial refutaron esas acusaciones. En uno, determinando que se estaba responsabilizando a las víctimas; en el otro que el tipo penal lesa humanidad se estaba aplicando incorrectamente. Estas rectificaciones terminaron por establecer la siguiente correlación: la responsabilidad por la violencia insurreccional no puede ser tipificada como un crimen contra la humanidad, y por regir el principio de prescripción de la acción penal, no puede ser castigada; al mismo tiempo, solo los agentes estatales pueden ser responsabilizados por cometer crímenes contra la humanidad. De este modo, durante los años de la reapertura, los argumentos que rechazaron la inculpación penal de las organizaciones armadas establecieron una frontera clara entre criminales y víctimas de los crímenes del pasado.

Para finalizar, queremos señalar que la única manera posible de comenzar a comprender el problema de la responsabilidad por la violencia del pasado reciente implica la recuperación de la premisa sobre la distinción entre los tipos de culpa que, tal como vimos en el caso de la reapertura de los juicios, estableció que la responsabilidad criminal es propia de los agentes estatales y que a los miembros de las organizaciones armadas solo pueden asumir su responsabilidad en términos morales o, en todo caso, políticos.

\section{Bibliografía consultada}

\section{Fuentes impresas}

Aboy Carlés Gerardo, Las dos fronteras de la democracia argentina. La reformulación de las identidades políticas de Alfonsín a Menem, Rosario, Homo Sapiens, 2001.

Acuña Carlos y Smulovitz Catalina, "Militares en la transición argentina: del gobierno a la subordinación constitucional”, Carlos Acuña, Inés González Bombal, Elizabeth Jelín, Luis

Alberto Quevedo, Catalina Smulovitz y Ana Vacchieri (eds.), Juicio, castigos y memorias. Derechos humanos y justicia en la política argentina, Buenos Aires, Nueva Visión, 1993. 
Andrioti Romanin Enrique, Memorias en conflicto. El movimiento de Derechos Humanos y la construcción del Juicio por la Verdad de Mar del Plata, Mar del Plata, Editorial de la Universidad de Mar del Plata, 2013.

Arendt Hannah, Eichmann en Jerusalén, Barcelona, De bolsillo, 2010.

Canelo Paula, La política secreta de la última dictadura argentina (1976-1983), Buenos Aires, Edhasa, 2016.

Confino Hernán, "Tensiones de un retorno: La Contraofensiva Estratégica Montonera de 1979 y 1980 en Argentina", Izquierdas, 28, 2016.

Crenzel Emilio, La historia política del Nunca Más: la memoria de las desapariciones en la Argentina, Buenos Aires, Siglo XXI, 2008.

Crenzel Emilio, "Ideas y estrategias de justicia ante la violencia política y las violaciones a los derechos humanos en la transición política en Argentina (1982-1983)", Claudia Feld y Marina Franco (Dir.), Democracia, hora cero. Actores, políticas y debates en los inicios de la posdictadura, Buenos Aires, Fondo de Cultura Económica, 2015, 81-114.

Feierstein Daniel, Juicios. Sobre la elaboración del genocidio II, Buenos Aires, Fondo de Cultura Económica, 2015, 59-64, 106-109.

Franco Marina, "La 'teoría de los dos demonios' en la primera etapa de la posdictadura", Claudia Feld y Marina Franco (Dir.), Democracia, hora cero. Actores, políticas y debates

en los inicios de la posdictadura, Buenos Aires, Fondo de Cultura Económica, 2015, 23-80. Filippini Leonardo, "La persecución penal en la búsqueda de justicia", Centro de Estudios Legales y Sociales y Centro Internacional para la Justicia Transicional, Hacer justicia: nuevos debates sobre el juzgamiento de crímenes de lesa humanidad en Argentina, Buenos Aires, Siglo XXI editores, 2011.

Guariglia Fabricio, "Crímenes internacionales y actores no estatales Centro de Estudios Legales y Sociales y Centro Internacional para la Justicia Transicional”, Hacer justicia: nuevos debates sobre el juzgamiento de crímenes de lesa humanidad en Argentina, Buenos Aires, Siglo XXI editores, 2011.

Guillespie Richard, Soldados de Perón. Historia crítica sobre los Montoneros, Buenos Aires, Sudamericana, 2008.

Jaspers Karl, El problema de la culpa. Sobre la responsabilidad política de Alemania, Barcelona, Ediciones Paidós, 1998. 
Jelín Elizabeth, "Les mouvements sociaux et le pouvoir judiciaire dans la lute contre l'impunité", Mouvements, 47-48, 2006/5.

Lorenzetti Ricardo y Kraut Alfredo, Derechos humanos: justicia y reparación. La experiencia de los juicios en Argentina, Buenos Aires, Sudamericana, 2011

Lvovich Daniel y Bisquert Jaquelina, La cambiante memoria de la dictadura. Discursos sociales y legitimidad democrática, Buenos Aires, Biblioteca Nacional/UNGS, 2008.

Montero Ana Soledad, ;Y al final un día volvimos! Los usos de la memoria en el discurso kirchnerista (2003-2007), Buenos Aires, Prometeo, 2012.

Nino Carlos, Juicio al mal absoluto, Buenos Aires, Emecé, 1997.

Novaro Marcos, "Derechos humanos y política democrática Las tareas de la historia y la justicia entre populismo y liberalismo", Pablo Eiroa y Juan Otero (comps.), Memoria y Derecho Penal, Buenos Aires, Fabian Di Placido Editor, 2008, 25-43.

Quaretti Lucía, ¿Quiénes merecen ser castigados? La configuración de un régimen de responsabilidad por la violencia del pasado reciente (Argentina, 2003-2007), Tesis para optar por el título de Magister en Ciencia Política, Buenos Aires, Instituto de Altos Estudios Sociales, Universidad Nacional de San Martin, 2017.

Salvi Valentina, De vencedores a víctimas. Memorias militares sobre el pasado reciente en la Argentina, Buenos Aires, Biblos, 2012.

Scatizza Pablo, Un Comahue violento: dictadura, represión y juicios en la norpatagonia argentina, Buenos Aires, Prometeo, 2016, 241.

Sikkink Kathryn, La cascada de la política. Cómo los juicios de lesa humanidad están cambiando el mundo de la política, México, Gedisa, 2013.

Varsky Carolina, Balardini Lorena, Martinez Daniel y Parella Julieta, "Justicia y memoria por delitos de lesa humanidad: un 2007 con más deudas que logros", Centro de Estudios Legales y Sociales, Derechos Humanos en Argentina, Informe 2007, Buenos Aires, Siglo XXI editores, 2008.

Vezzetti Hugo, Pasado y presente. Guerra, dictadura y sociedad en Argentina, Buenos Aires, Siglo XXI Editores, 2002.

Vezzetti Hugo, Sobre la violencia revolucionaria memorias y olvidos, Buenos Aires, Siglo XXI editores, 2009. 
Yanzón Rodolfo, 2011, "Los juicios desde el fin de la dictadura hasta hoy", Gabriel Andreozzi (coord.), Los juicios por los crímenes de lesa humanidad en Argentina, Buenos Aires, Atuel, 2011.

\section{Fuentes digitales}

Confino Hernán, "La contraofensiva estratégica montonera en las memorias de sus participantes: Crónica de un objeto polémico", Aletheia, 6, 11, 2015, 1-22. Recuperado de: http:// www.memoria.fahce.unlp.edu.ar/art_revistas/pr.6969/pr.6969.pdf

Guthmann Yanina, "Sociedad civil y derecho internacional de los derechos humanos en Argentina" Perfiles latinoamericanos, 16, 32, 2008. Recuperado de: http://www.scielo.org.mx/scielo.php?pid=S0188- 76532008000200006\&script=sci_arttext. Letner Gustavo, Dolo eventual y culpa con representación, Corte Interamericana de Derechos Humanos, 2015. Recuperado de: http://www.corteidh.or.cr/tablas/22233a.pdf 